\title{
Iron Overload in a Patient with Non-Transfusion-Dependent Hemoglobin H Disease and Borderline Serum Ferritin: Can We Rely on Serum Ferritin for Monitoring in This Group of Patients?
}

\author{
Mohammad Ali ${ }^{a} \quad$ Mohamed A. Yassin ${ }^{b}$ Maya Aldeeb ${ }^{a}$ \\ aDepartment of Medical Education, Hamad Medical Corporation, Doha, Qatar; ${ }^{b}$ Department \\ of Medical Oncology, Hematology Section, National Center for Cancer Care and Research, \\ Hamad Medical Corporation, Doha, Qatar
}

Keywords

Hemoglobin $\mathrm{H}$ disease $\cdot$ Liver iron concentration

\begin{abstract}
Secondary iron overload is a common complication in the context of hematological diseases, as iron accumulates due to different mechanisms including chronic transfusion, increased gastrointestinal absorption, chronic hemolysis and underlying genetic defects leading to an increase in gastrointestinal absorption of iron. Since the body does not have a mechanism to excrete excess iron, it gets deposited in the heart, endocrine organs, and the liver with the latest being affected less commonly than in primary iron overload disorders like hemochromatosis. Patients with hemoglobin $\mathrm{H}$ disease, which is a type of $\alpha$-thalassemia, are usually transfusion independent, except in occasions where an external stressful factor leads to a drop in hemoglobin and necessitates blood transfusion. Despite this, secondary iron overload is commonly encountered in these patients due to increased gastrointestinal absorption of iron. To avoid the complications associated with iron overload, these patients are usually monitored with serum ferritin, which is an inexpensive widely available method to monitor iron overload. MRI of the liver (Ferriscan) is a more sensitive and specific method to monitor these patients and avoid the long-lasting and sometimes irreversible effect of secondary iron overload. Here we present an interesting case of a patient with hemoglobin $\mathrm{H}$ disease, who was monitored with serum ferritin. She had a serum ferritin level considered as a borderline risk for morbidities secondary to iron overload, and an MRI of her liver (Ferriscan) showed significant iron deposition in the liver associated with increased risk of complications secondary to iron overload.


Ali et al.: Iron Overload in a Patient with Non-Transfusion-Dependent $\mathrm{HbH}$ and Borderline Serum Ferritin

\section{Introduction}

Hemoglobin is a tetramer molecule consisting of two $\alpha$-globin chains, two $\beta$-globin chains, and the iron containing tetrapyrrole heme moiety. Production of $\alpha$ - and $\beta$-chains normally occurs in a balanced manner from genes located on chromosome 16 and 11, respectively. Thalassemias are a group of inherited hemoglobinopathies characterized by a reduced production of the $\alpha$ - or $\beta$-chains used for synthesis of the hemoglobin molecule. Mismatched production of either $\alpha$ or $\beta$ results in impaired production of hemoglobin and ineffective erythropoiesis [1].

The prevalence of thalassemia varies by the geographic location, and it is most common in Africa, Mediterranean countries, and Southeast Asia. The prevalence of thalassemia in Qatar according to a local study is $30 \%$ for $\beta$-thalassemia and $12.8 \%$ for $\alpha$-thalassemia [2].

A single $\alpha$ gene mutation will lead to a silent carrier status and affected individuals are healthy without an underlying anemia. A two-gene mutation results in $\alpha$-thalassemia characterized by a hemoglobin level of approximately $10 \mathrm{~g} / \mathrm{dL}$ with microcytosis and normal hemoglobin electrophoresis. A three-gene mutation will lead to a tetramer of $\beta$-globin called hemoglobin $\mathrm{H}(\mathrm{HbH})$ detected on hemoglobin electrophoresis, and a more severe anemia of 7-8 $\mathrm{mg} / \mathrm{dL}$ approximately. A four-gene mutation is incompatible with life and leads to hydrops fetalis [2].

$\mathrm{HbH}$ precipitate in the bone marrow leads to ineffective erythropoiesis and in the peripheral circulation to hemolysis. As a result, affected individuals have variable degrees of anemia and extramedullary hematopoiesis, which in turn can cause bone changes, and secondary iron overload. Typically affected individuals are transfusion-independent but can occasionally require blood transfusion transiently due to infections or aplastic crisis. Laboratory findings in patients with $\mathrm{HbH}$ disease include microcytic anemia, nucleated erythrocytes, and target cells on peripheral smear. Also, red blood cell count is usually high leading to a Mentzer index (MCV/RBC count) of less than 13. Other laboratory findings include high $\mathrm{LDH}$, low haptoglobin and high indirect bilirubin, which are consistent with peripheral hemolysis usually seen in this disorder [3].

In the context of hematological diseases, secondary iron overload develops most commonly secondary to chronic blood transfusion [4-6]. However, patients with $\mathrm{HbH}$ disease are typically transfusion-independent except for occasional blood transfusion intermittently. Despite this, around $70 \%$ of individuals with $\mathrm{HbH}$ disease develop some degree of iron overload by adulthood, even with minimal or no transfusion history. This is explained by ineffective erythropoiesis leading to inappropriately low hepcidin level and subsequently to an increase in the absorption of iron from the gastrointestinal tract [7-10].

The gold standard method to assess iron overload is the liver iron concentration (LIC) determined by liver biopsy. A standardized MRI method (Ferriscan) is a reasonable noninvasive method to assess LIC with high sensitivity and specificity (94 and 100\%, respectively). An LIC level of up to $5 \mathrm{mg} / \mathrm{g}$ of liver dry weight is not associated with a significant adverse effect. Serum ferritin is another non-invasive method to assess liver iron stores. A cutoff value of $300 \mu \mathrm{g} / \mathrm{L}$ in males and $200 \mu \mathrm{g} / \mathrm{L}$ in females is usually consistent with an iron overload, and a value of more than $800 \mu \mathrm{g} / \mathrm{L}$ in non-transfusion-dependent thalassemia patients is associated with an increased risk of morbidity. Serum ferritin is a sensitive test for iron overload, but it is not very specific because numerous conditions other than iron overload can lead to elevations in serum ferritin; however it is widely used for monitoring patients as it is inexpensive and more accessible [10].

Here we present an interesting case of a non-transfusion-dependent patient known to have $\mathrm{HbH}$ disease and being monitored with serum ferritin for secondary iron overload. 
Ali et al.: Iron Overload in a Patient with Non-Transfusion-Dependent $\mathrm{HbH}$ and Borderline Serum Ferritin

Despite the serum ferritin level not being consistent with increased risk of morbidity, she was found to have a high LIC on liver MRI (Ferriscan), which placed her at a high risk of complications secondary to iron deposition in the body organs.

\section{Case Presentation}

A 44-year-old female patient known to have $\mathrm{HbH}$ disease had been followed up in our clinic for the past 5 years. She was monitored with serum ferritin every 6 months. Her baseline serum ferritin at her initial visit was $750 \mu \mathrm{g} / \mathrm{L}$, which is consistent with iron overload, but not consistent with an increased risk of morbidity from iron overload, which usually develop with serum ferritin of more than $800 \mu \mathrm{g} / \mathrm{L}$.

Later on a follow-up visit, she had a slight increase in her serum ferritin up to $780 \mu \mathrm{g} / \mathrm{L}$, so it was decided to repeat the liver MRI (Ferriscan) and it showed an LIC of $7 \mathrm{mg} / \mathrm{g}$ of dry liver weight, which is consistent with increased risk of complications secondary to iron overload. The patient was started on oral deferasirox (Jadenu formulation) and continued to be followed up with repeated serum ferritin. She tolerated the medication without any adverse effect, and her repeated serum ferritin level came down significantly to $250 \mu \mathrm{g} / \mathrm{L}$ after 6 months.

To monitor for endocrine gland dysfunction, which is common in patients with secondary iron overload, this patient has been followed up with fasting blood glucose, IGF (insulin-like growth factor 1) and thyroid function test every 6 months to 1 year. Fortunately, these results of these tests were normal and did not indicate an underlying endocrine dysfunction.

\section{Discussion}

The imbalance in the normal ratio of $\alpha$ - to $\beta$-chains leads to precipitation of $\mathrm{HbH}$, which causes destruction of red blood cell precursors in the bone marrow resulting in ineffective erythropoiesis and in the circulation resulting in a variable degree of hemolysis [2]. Affected individuals express a variable degree of anemia and extramedullary hematopoiesis, leading to bone changes, secondary iron overload $[11,12]$, and various endocrine gland dysfunction secondary to iron overload. The clinical severity of anemia in $\mathrm{HbH}$ disease is variable, and individuals are typically transfusion-independent but can deteriorate into transfusion dependence during periods of increased hemolysis due to infection, pregnancy, or aplastic crisis. Despite this, around $70 \%$ of individuals with $\mathrm{HbH}$ disease develop some degree of iron overload by adulthood. The buildup of iron in the body over a long period of time leads to its deposition in the heart, various endocrine glands, and the liver [3].

Secondary iron overload occurs due to different mechanisms depending on the underlying medical condition. In the context of hematological diseases, iron most commonly deposits in the body due to chronic blood transfusion as seen in patients with $\beta$-thalassemia major. In case of non-transfusion-dependent thalassemia like $\beta$-thalassemia intermedia and $\mathrm{HbH}$ disease, iron overload can develop due to ineffective erythropoiesis leading to an inappropriately low hepcidin level and subsequently to an increase in the absorption of iron from the gastrointestinal tract [12]. A different mechanism is observed in non-transfusiondependent sickle cell disease where excess iron deposits in body organs due to chronic hemolysis and subsequent increase in intestinal absorption of iron [4]. Finally, excessive iron deposition is seen in acquired bone marrow failure conditions such as myelodysplastic syndrome due to genetic mutation leading to suppression of the hepcidin level causing an increase in iron absorption from the gastrointestinal tract [6]. 
Ali et al.: Iron Overload in a Patient with Non-Transfusion-Dependent $\mathrm{HbH}$ and Borderline Serum Ferritin

The gold standard method to assess for iron overload, in the absence of liver cirrhosis, is the LIC determined by liver biopsy. A standardized MRI method (Ferricscan) is a reasonable non-invasive method to assess LIC with high sensitivity and specificity ( 94 and 100\%, respectively). The normal LIC is between 0.4 and $2.2 \mathrm{mg} / \mathrm{g}$ of dry liver weight, an LIC level up to $5 \mathrm{mg} / \mathrm{g}$ of liver dry weight is not associated with significant adverse effect, while values $>15$ $\mathrm{mg} / \mathrm{g}$ are being consistently associated with liver cirrhosis. Serum ferritin is an inexpensive method to assess liver iron store, making it a more accessible method especially in resourcepoor countries. A cutoff value of $300 \mu \mathrm{g} / \mathrm{mL}$ in male and $200 \mu \mathrm{g} / \mathrm{mL}$ in female is usually consistent with iron overload.

In chronically transfused patients, trends in serum ferritin are helpful to monitor changes in iron stores. However, intersubject variability is quite high and ferritin values may change disparately from trends in total body iron load over periods of several years. In a study that compared hepatic iron stores and plasma ferritin concentration in patients with sickle cell anemia and thalassemia major treated with red cell transfusion and iron chelation therapy, hepatic iron stores were measured with MRI, and plasma ferritin was determined by immunoassay. Regression analysis found that variation in hepatic iron stores accounted for only approximately $57 \%$ of the variation in plasma ferritin, suggesting that the remainder was the result of other factors, such as hemolysis, ineffective erythropoiesis, ascorbate deficiency, inflammation, and liver disease. Variability resulting from factors other than iron status limits the clinical usefulness of the plasma ferritin concentration as a predictor of body iron stores.

In non-transfusion-dependent thalassemia, serum ferritin values are found to be lower than transfusion-dependent thalassemia for the same degree of LIC, and thus they underestimate the iron burden. Studies have shown that in non-transfusion-dependent thalassemia patients, serum ferritin values of $>800 \mu \mathrm{g} / \mathrm{L}$ and $<300 \mu \mathrm{g} / \mathrm{L}$ are associated with an increased and absence of risk for morbidity, respectively. Here we report a different observation, as our patient had a serum ferritin of $762 \mu \mathrm{g} / \mathrm{L}$, while a Ferriscan done on her showed an LIC of $7 \mathrm{mg} / \mathrm{g}$, which means that she was at a considerable risk of morbidity from iron overload despite of a borderline serum ferritin level. Effective monitoring and early identification of iron overload is of outmost importance in these patients as cardiomyopathy and decompensated liver disease due to iron deposition are largely irreversible. In addition to that, many endocrine complications can develop, which would lead to a lifelong morbidity in a relatively young population of patients $[5,13,14]$.

Endocrine complications are more common in secondary causes of iron overload compared to primary causes, and as a result, various metabolic complications can develop. One study found a higher prevalence of glucose dysregulation in patients with acute and chronic hematological malignancies requiring repeated transfusions, and FBG was correlated significantly with the amount of iron transfused and ALT level [6]. Moreover, thyroid dysfunction is a known complication of iron overload; a study done on patients with $\beta$-thalassemia major showed worsening of thyroid function in $35 \%$ of the study population by the age of 18 years. Another study showed that $7.6 \%$ of patients with thalassemia major developed central hypothyroidism [15].

Other endocrine complications include short stature and hypogonadotropic hypogonadism as observed in a study of 28 adolescent patients with thalassemia intermedia, $25 \%$ of patients in the study had short stature, and $10.7 \%$ had hypogonadotropic hypogonadism with no difference between non-transfused versus infrequently transfused patients [14, 16, 17]. The association between iron overload and short stature was supported by another study showing that $50 \%$ of thalassemia major patients had IGF-1 2 SD below the average value for healthy individuals [18]. In addition to that, iron overload and chronic liver disease play an important role in the development of hypogonadotropic organism according to a study done on 11 patients with thalassemia major and hypogonadotropic hypogonadism [13]. 
Deferasirox, whether the conventional or the new formula Jadenu, is useful to treat iron overload in such a category of patients [19].

\section{Conclusion}

Secondary Iron overload is common in patients with $\mathrm{HbH}$ disease, and it can lead to irreversible damage when iron accumulates in the heart leading to cardiomyopathy or in the liver leading to cirrhosis. A more frequent problem is endocrine gland dysfunction, and the development of this complication in a relatively young patient population is worrisome as it leads to long-lasting effects on growth and development.

Based on our observation, we advocate for the use of MRI of the liver (Ferriscan) to monitor patients with non-transfusion-dependent thalassemia as it is more specific for the diagnosis of iron overload. In resource-poor countries where health care cost is a limiting factor, it is important to start iron chelating therapy early and to monitor for endocrine gland dysfunction regularly.

\section{Acknowledgment}

The authors would like to acknowledge the Internal Medicine and Hematology Department at Hamad Medical Corporation for supporting this publication.

\section{Statement of Ethics}

Written informed consent was obtained from both patients to allow the publication of information including images. The case was approved by the HMC Medical Research Center.

\section{Disclosure Statement}

The authors report no conflicts of interest in this work.

\section{Funding Sources}

The Qatar National Library funded this study.

\section{Authors Contribution}

The authors contributed equally in writing and editing. 
Ali et al.: Iron Overload in a Patient with Non-Transfusion-Dependent $\mathrm{HbH}$ and Borderline Serum Ferritin

\section{References}

1 De Sanctis V, Kattamis C, Canatan D, Soliman AT, Elsedfy H, Karimi M, et al. $\beta$-Thalassemia distribution in the Old World: an ancient disease seen from a historical standpoint. Mediterr J Hematol Infect Dis. 2017; 9(1):e2017018.

2 Kamal M, Abu Sariya S, Abu-Dayya A, Al-Khatib H, Abu-Ramadan H, Petrou M. The molecular basis of $\alpha$-thalassemia in Qatari pediatric population. Hemoglobin. 2015;39(5):350-4.

3 Chui DH, Fucharoen S, Chan V. Hemoglobin H disease: not necessarily a benign disorder. Blood. 2003 Feb 1; 101(3):791-800.

4 Yassin M, Soliman A, De Sanctis V, Nashwan A, Abusamaan S, Moustafa A, et al. Liver iron content (LIC) in adults with sickle cell disease (SCD): correlation with serum ferritin and liver enzymes concentrations in trasfusion dependent (TD-SCD) and non-transfusion dependent (NT-SCD) patients. Mediterr J Hematol Infect Dis. 2017;9(1):e2017037.

5 Kanbour I, Chandra P, Soliman A, De Sanctis V, Nashwan A, Abusamaan S, et al. Severe Liver Iron Concentrations (LIC) in 24 Patients with $\beta$-Thalassemia Major: Correlations with Serum Ferritin, Liver Enzymes and Endocrine Complications. Mediterr J Hematol Infect Dis. 2018;10(1):e2018062.

6 Yassin MA, Soliman A, De Sanctis V, Hmissi SM, Abdulla MAJ, Ekeibed Y, et al. The impact of iron overload in patients with acute leukemia and myelodysplastic syndrome on hepatic and endocrine functions. Acta Biomed. 2018;89(3-S):18-22.

7 Karimi M, Zarei T, Haghpanah S, Azarkeivan A, Kattamis C, Ladis V, et al. Evaluation of endocrine complications in beta-thalassemia intermedia ( $\beta$-TI): a cross-sectional multicenter study. Endocrine. 2019 Dec 18:1-8.

8 Ali M, Yassin MA. Iron overload in patients with chronic lymphocytic leukemia complicated by autoimmune hemolytic anemia: a case report. Case Rep Oncol. 2020;13(1):219-24.

9 Hamamyh T, Yassin MA. Autoimmune Hemolytic Anemia After Relapse of Chronic Myeloid Leukemia: A Case Report. Clin Med Insights Blood Disord. 2019 Dec;12:1179545X19894578.

10 Yassin M, Soliman A, De Sanctis V, Aldewik N, Knuth K, Elsotouhy A, et al. Hereditary Hemochromatosis in an Adult Due to H63D mutation: The value of Estimating Iron deposition by MRI T2* and Dissociation between Serum Ferritin Concentration and Occurrence of Complications. Jokull J. 2014;124(21):4891.

11 De Sanctis V, Soliman AT, Elsedfy H, Yassin M, Canatan D, Kilinc Y, et al. Osteoporosis in thalassemia major: an update and the I-CET 2013 recommendations for surveillance and treatment. Pediatr Endocrinol Rev. 2013; 11(2):167-80.

12 Abdulla MAJ, Yassin MA, Abdelrazek M, Mudawi D, Ibrahim F, Soliman DS, et al. A persistent cough as atypical clinical presentation of intrathoracic extramedullary hematopoiesis (EMH) in a female with thalassemia intermedia. Acta Biomed. 2018;89(2-S):41-6.

13 Soliman A, Yassin M, Al Yafei F, Al-Naimi L, Almarri N, Sabt A, et al. Longitudinal study on liver functions in patients with thalassemia major before and after deferasirox (DFX) therapy. Mediterr J Hematol Infect Dis. 2014;6(1):e2014025.

14 De Sanctis V, Soliman AT, Candini G, Yassin M, Raiola G, Galati MC, et al. Insulin-like growth factor-1 (IGF-1): Demographic, clinical and laboratory data in 120 consecutive adult patients with thalassaemia major. Mediterr J Hematol Infect Dis. 2014;6(1):e2014074.

15 Soliman AT, Al Yafei F, Al-Naimi L, Almarri N, Sabt A, Yassin M, et al. Longitudinal study on thyroid function in patients with thalassemia major: High incidence of central hypothyroidism by 18 years. Indian J Endocrinol Metab. 2013 Nov;17(6):1090-5.

16 De Sanctis V, Soliman A, Candini G, Campisi S, Anastasi S, Iassin M. High prevalence of central hypothyroidism in adult patients with $\beta$-thalassemia major. Georgian Med News. 2013 Sep;(222):88-94.

17 De Sanctis V, Elsedfy H, Soliman AT, Elhakim IZ, Pepe A, Kattamis C, et al. Acquired hypogonadotropic hypogonadism $(\mathrm{AHH})$ in thalassaemia major patients: an underdiagnosed condition? Mediterr J Hematol Infect Dis. 2016;8(1):e2016001.

18 Yassin MA, Soliman AT, De Sanctis V, Yassin KS, Abdulla MA. Final Height and Endocrine Complications in Patients with $\beta$-Thalassemia Intermedia: Our Experience in Non-Transfused Versus Infrequently Transfused Patients and Correlations with Liver Iron Content. Mediterr J Hematol Infect Dis. 2019;11(1):e2019026.

19 Yassin MA, Soliman AT, De Sanctis V, Hussein RM, Al-Okka R, Kassem N, et al. Jadenu $®$ substituting Exjade $®$ in iron overloaded $\beta$-thalassemia major (BTM) patients: a preliminary report of the effects on the tolerability, serum ferritin level, liver iron concentration and biochemical profiles. Mediterr J Hematol Infect Dis. 2018; $10(1)$. 